\title{
Modelo 2D de resistividade para o Campo de Carmópolis, Bacia SEAL, utilizando o Método Magnetotelúrico
}

\author{
${ }^{*}$ Gomes, K.C.P. ${ }^{3}$; Corrêa, E.O. ${ }^{1,2}$; de Lugão, P.P.L. ${ }^{1}$; Kriegshäuser, B.F. ${ }^{1}$; Menezes, A.M.C. ${ }^{1}$; Nunes, D.F. ${ }^{1}$; de Oliveira, \\ A.R.R. ${ }^{1}$; da Rocha, L.M.S. ${ }^{1}$ \\ ${ }^{1}$ Strataimage Consultoria Ltda. \\ ${ }^{2}$ UERJ - Programa de Pós-Graduação em Análise de Bacias e Faixas Móveis. \\ ${ }^{3}$ UENF/LENEP - Programa de Pós-Graduação em Engenharia de Reservatório e de Exploração.
}

Copyright 2018, SBGf - Sociedade Brasileira de Geofísica

Este texto foi preparado para a apresentação no VIII Simpósio Brasileiro de Geofísica, Salinópolis, 18 a 20 de setembro de 2018. Seu conteúdo foi revisado pelo Comitê Técnico do VIII SimBGf, mas não necessariamente representa a opinião da SBGf ou de seus associados. É proibida a reprodução total ou parcial deste material para propósitos comerciais sem prévia autorização da SBGf.

\section{Resumo}

Foi realizado um projeto de aquisição de dados magnetotelúricos (MT) composto por 93 estações ao longo de cinco perfis cobrindo a porção SE da Bacia Sergipe - Alagoas. O estudo foi concentrando no domínio onshore da Sub-Bacia de Sergipe para fazermos uma correlação de novos dados de resistividade com as informações existentes.

O modelo 2D de resistividade em profundidade apresentou uma boa correlação com os modelos evolutivos da Bacia Sedimentar, com eficaz correlação no limite Embasamento - Bacia Sedimentar. Análise do modelo 2D com o campo exploratório em atividade, Campo de Carmópolis, nota-se um padrão peculiar: sistemas petrolíferos flanqueados por condutores de baixa resistividade e encaixados em falhas normais. Esta arquitetura confirma os condutos de migração vertical petrolífero podendo ser utilizada como modelo de identificação ao longo de outras seções.

PALAVRAS-CHAVE: magnetotelúrico, exploração de óleo e gás, Bacia de Sergipe-Alagoas.

\section{Introdução}

O Campo de Carmópolis, com 268 milhões de metros cúbicos de óleo original in situ (fonte: ANP 10를 Rodada), é o maior e mais importante da Bacia Sergipe - Alagoas. Visando melhorar a compreensão do sistema petrolífero na área, foi realizado um projeto de aquisição de dados magneto-telúricos (MT) com o objetivo de correlacionar os novos dados de resistividade com as informações existentes.

O método magnetotelúrico (MT) mede as componentes dos campos elétricos e magnéticos na superfície terrestre para obtenção dos parâmetros resistividade aparente e fase. O método utiliza a variação temporal natural do campo magnético da Terra como fonte geradora de sinais. Sendo assim, o método é isento de qualquer dano ao meio-ambiente, pois não gera qualquer tipo de sinal e as estações podem ser instaladas sem desmatamento de áreas e próximas a áreas urbanas. Foram adquiridas 93 estações MT ao longo de cinco perfis (figura 1) cobrindo a porção SE da Bacia SEAL.

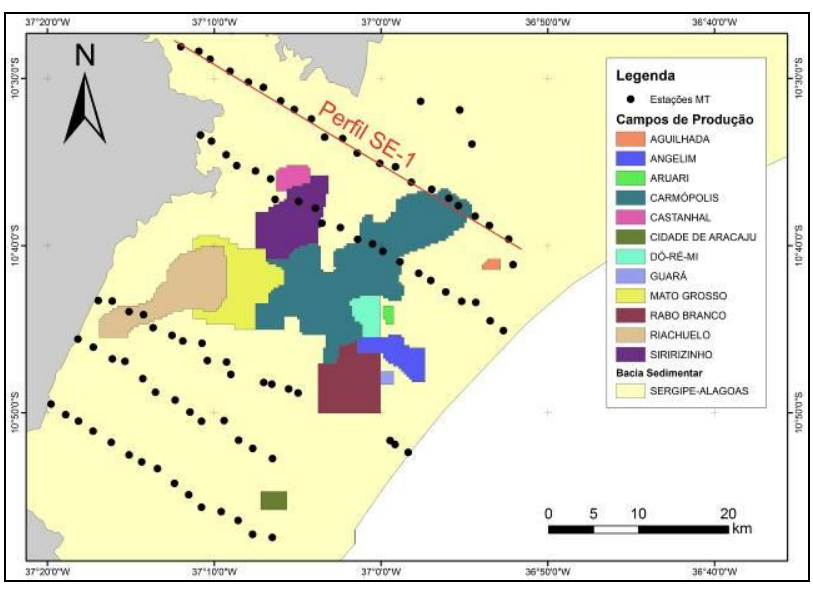

Figura 1: Localização das 93 estações MT na Bacia SEAL, perfil SE-1 e os principais campos de produção em Sergipe.

Neste trabalho apresentaremos o perfil SE1, que cruza a porção nordeste do campo de Carmópolis na direção NW-SE e possui 22 estações ao longo de $48 \mathrm{~km}$, com espaçamento em torno de $2.0 \mathrm{~km}$. O foco do trabalho foi definir as relações entre as sequências sedimentares da bacia, a interação tectônica entre a borda da bacia com embasamento e o seu arcabouço estrutural para corroborar com um melhor entendimento das condições no Campo de Carmópolis. O Campo de Carmópolis foi detalhado, considerando as suas heterogeneidades particulares, em relação às rochas reservatório e características estruturais mapeadas pela resposta do método geofísico.

O modelo 2D de resistividade em profundidade apresentou uma boa correlação com os modelos evolutivos da Bacia Sedimentar, com eficaz correlação no limite Embasamento - Bacia Sedimentar. Estruturalmente foram delimitadas as principais estruturas da região, apresentando falhas normais com direções de mergulho alternantes entre NW e SE na seção. Ao analisar a seção SE1 com o campo exploratório em atividade, Campo de Carmópolis, nota-se um padrão peculiar: sistemas 
petrolíferos flanqueados por condutores de baixa resistividade e encaixados em falhas normais.

\section{Metodologia/ Problema Investigado}

O método magnetotelúrico (MT) e sua variante de alta frequência audio-magnetotelúrico (AMT) medem os campos elétricos e magnéticos na superfície terrestre para obtenção do tensor de impedância.

O método utiliza a variação temporal natural do campo magnético da Terra como fonte geradora de sinais. Essas variações englobam a faixa de frequência desde $10 \mathrm{KHz}$ até cerca de $0.0001 \mathrm{~Hz}$. Sendo assim, o método é isento de quaisquer dano ao meio-ambiente pois não gera qualquer tipo de sinal e as estações podem ser instaladas sem desmatamento de áreas.

Os canais telúricos (campo elétrico Ex e Ey) são medidos com dipolos de $100 \mathrm{~m}$ para o AMT e para o MT, em configuração cruzada, utilizando eletrodos porosos nãopolarizáveis de cloreto de chumbo. A variação dos campos magnéticos ( $\mathrm{Hx}, \mathrm{Hy}$ e $\mathrm{Hz}$ ) é medida com o uso de bobinas de indução de alta sensibilidade. Os campos elétricos $(E)$ e magnéticos $(H)$ ortogonais registrados são alinhados para norte (Ex, Hy) e leste (Ey, Hx) magnéticos orientados por bússola (Figura 2).

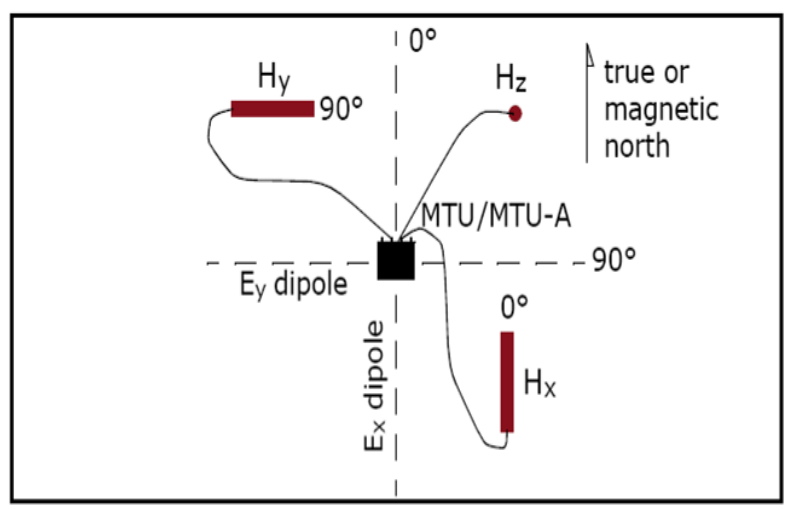

Figura 2: Configuração de uma estação para aquisição de dados magnetotelúricos.

Os dados MT/AMT são adquiridos como séries temporais, ou seja, variações das componentes do campo elétrico (Ex, Ey) e magnético $(\mathrm{Hx}, \mathrm{Hy}, \mathrm{Hz})$ com o tempo. A Figura 3 mostra um exemplo de janela de uma série temporal com as cinco componentes do campo eletromagnético.

A escolha entre AMT e MT e o tempo de aquisição vai depender da profundidade de investigação e da geologia do meio. Uma aquisição AMT dura cerca de uma hora, enquanto que uma aquisição MT pode levar dias, as estações MT adquiridas nesse trabalho tem duração de $24 \mathrm{~h}$.

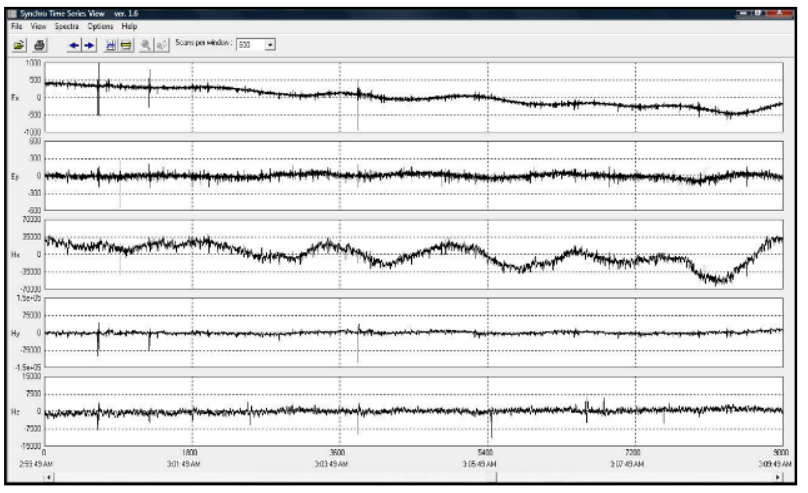

Figura 3: Exemplo de dados brutos MT como séries temporais das componentes dos campos $E$ e $H$.

O processamento dos dados é realizado diariamente. As séries temporais são transformadas para o domínio da frequência através de Transformada de Fourier e o tensor de impedância $(Z)$ é calculado.

Os elementos do tensor impedância Z são calculados no domínio da frequência a partir da relação entre as componentes horizontais dos campos incidentes e induzidos:

\section{$Z x y=E x / H y$ e $Z y x=E y / H x$}

A partir do tensor impedância são calculados os principais parâmetros utilizados na interpretação: resistividade aparente e fase para dois modos de

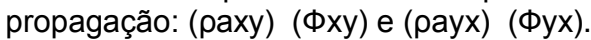

A Figura 4 mostra exemplo de dados reais de resistividade aparente e fase e modelo 1D de resistividade em profundidade para uma estação deste projeto.

As Figuras 5 e 6 mostram o equipamento utilizado para aquisição MT/AMT, sendo que para o AMT são utilizadas as bobinas menores (AMTC-30) com faixa de frequência $10 \mathrm{KHz}$ a $1 \mathrm{~Hz}$ e para o MT bobinas maiores (MTC-50H) com faixa de frequência entre $400 \mathrm{~Hz}$ e $2.000 \mathrm{~s}$ (Figura 2.5). 
${ }^{*}$ Gomes, K.C.P. ${ }^{3}$; Corrêa, E.O. ${ }^{1}$; de Lugão, P.P.L. ${ }^{1}$; Kriegshäuser, B.F. ${ }^{1}$; Menezes, A.M.C. ${ }^{1}$; Nunes, D.F. ${ }^{1}$; de Oliveiræß A.R.R. ${ }^{1}$; da Rocha, L.M.S. ${ }^{1}$

${ }^{1}$ Strataimage Consultoria Ltda.

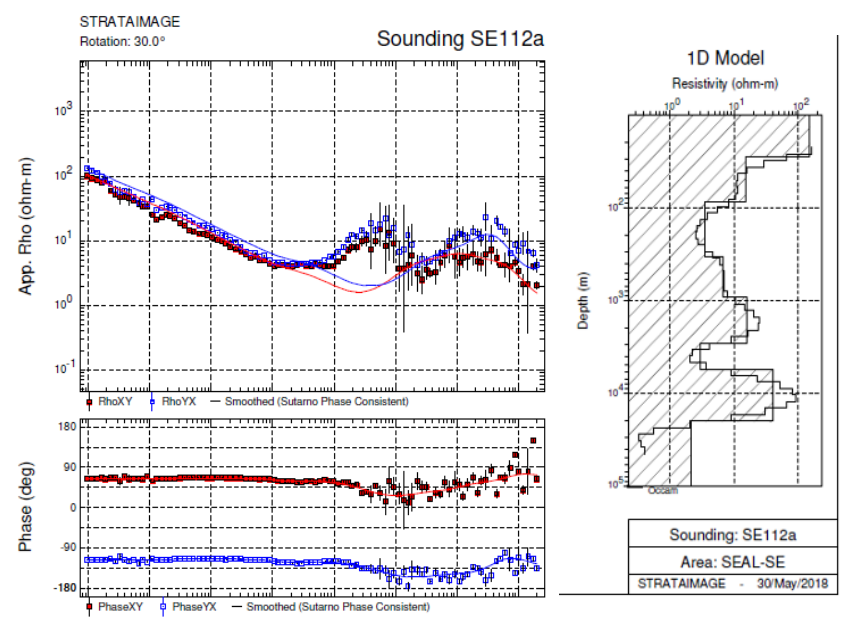

Figura 4: Exemplo de dados processados, resistividade aparente e modelo $1 D$ para este projeto.

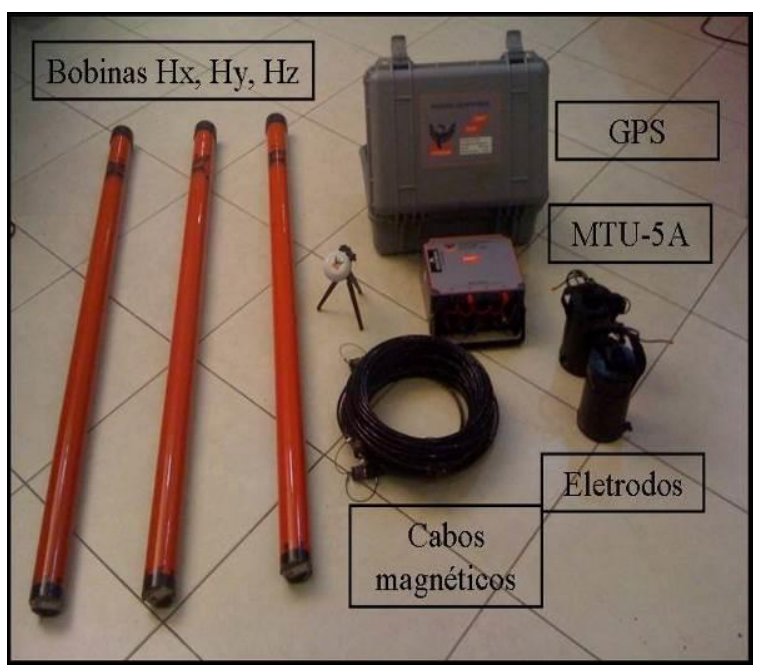

Figura 5: Sistema de aquisição MTU-5A fabricado pela Phoenix Geophysics do Canadá.

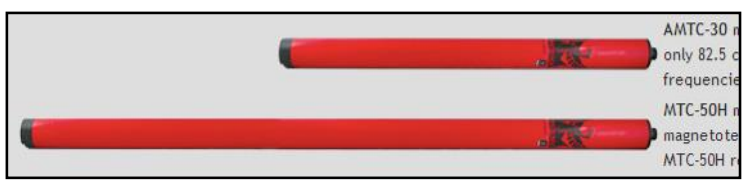

Figura 6: Bobinas AMTC-30 para AMT e MTC-50H aquisição $M T$.

\section{Geologia da área}

A seção geológica encontra-se tanto no contexto da faixa de dobramentos sergipana como na seção donw-dip da sub-bacia de Sergipe (Figura 7). O embasamento é constituído por rochas metamórficas proterozóicas da Faixa Sergipana, granitóides proterozóicos do Maciço Pernambuco-Alagoas e metassedimentos do Grupo Macururé (Teixeira et al, 2014).

Em relação à bacia sedimentar temos: sequência sinéclise, constituída por rochas Formação Batinga e Formação Aracaré com ambientes de sedimentação continentais; sequência pré-rifte, constituída por arenitos da Formação Candeeiro e folhelhos vermelhos lacustres da Formação Bananeiras e arenitos da Formação Serraria; sequência rifte, composta na base por folhelhos e arenitos lacustres da Formação Feliz Deserto. A discordância Pré-Aratu separa estes dos folhelhos da Formação Barra de Itiúba; este pacote sedimentar grada lateralmente para arenitos da Formação Penedo e conglomerados, denominados Formação Rio Pitanga. Sobreposto a este pacote encontram-se os bancos carbonáticos do Membro Morro do Chaves e clásticos terrígenos flúvio-deltaicos da Formação Coqueiro Seco. O topo da sequência rifte é dado pelos arenitos e folhelhos da Formação Maceió; sequência pós-rifte, corresponde a primeira grande incursão marinha da bacia, com a deposição da Formação Muribeca. Litoestratigraficamente é composta por siliciclásticos grossos do Membro Carmópolis, evaporitos, carbonatos e folhelhos do Membro lbura e folhelhos e calcilutitos do Membro Oiteirinhos; sequência drifte compreende dois intervalos, um basal transgressivo e outro superior regressivo. O primeiro intervalo é constituído por sedimentação predominantemente carbonáticas das Formações Riachuelo e Cotinguiba. $O$ intervalo regressivo registra um sistema deposicional predominantemente clástico, constituído pelos arenitos da Formação Marituba, carbonatos da Formação Mosqueiro e folhelhos com arenitos turbidíticos da Formação Calumbi (Campos Neto et al, 2007).

O campo de Carmópolis encontra-se envolvido no sistema petrolífero Muribeca, que possuí grande parte de suas acumulações no Alto de Aracaju. As rochas geradoras desse sistema são os folhelhos pretos do Membro lbura, da Formação Muribeca, os altos estruturais funcionam como trapas e os reservatórios são embasamento fraturado e os conglomerados da Formação Muribeca. Os selos desse sistema são os evaporitos e folhelhos da mesma formação. Os reservatórios de Carmópolis são divididos em dois tipos, um composto pelo reservatório sendo embasamento fraturado e outro composto por reservatórios na Formação Muribeca, na presença de arenitos e folhelhos, e Formação Barra de Itiúba, constituídos por arenitos de alta porosidade, cruzados pelo levantamento geofísico. Possuem um aquífero atuante nas bordas do campo e não ocorre presença de capa de gás (Milani e Araújo, 2003). 


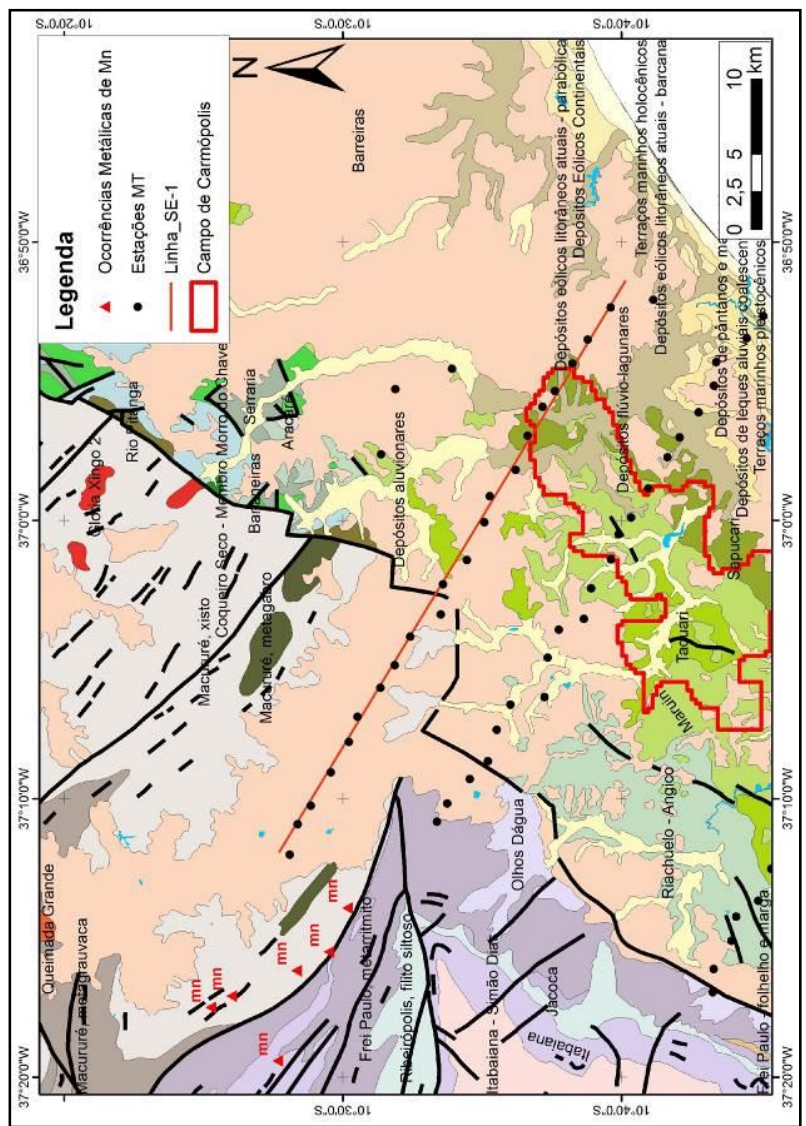

Figura 7: Geologia de superfície, com localização do perfil MT do trabalho, estações realizadas no projeto, campo de Carmópolis.

\section{Resultados e Discussões}

O presente modelo geofísico demonstra com qualidade, a arquitetura deposicional da área estudada em forma de uma seção de resistividade vs profundidade. Podendo separar a seção em duas grandes regiões, uma englobando o contexto da bacia sedimentar e outro o contexto da Faixa Sergipana (figura 8).

Em relação a faixa de dobramentos sergipana, a inversão exibe as rochas do Grupo Macururé apresentando uma alta resistividade em sua porção superior (> 500 Ohm.m), seguida por resistividades intermediárias e a presença de um condutor bem restrito. A interpretação para esta seção é que ocorrem os xistos granatíferos ricos em quartzo com uma alta resistividade no topo da seção, sobrepostos a sucessão metassedimentar composta pelas metagrauvacas e metarritimitos do mesmo grupo. O condutor observado foi interpretado como uma possível mineralização de metálicos, provavelmente manganês, visto sua semelhança com as ocorrências presentes em alguns lineamentos estruturais associados à metagabros em superfície.
Em relação à sub-bacia de Sergipe, foi possível delimitar - embasamento e o contexto sedimentar que está envolvido. A base da seção (indicada pelas cores azuis, faixa de alta resistividade: valores acima de 150 ohm.m) compõe o embasamento Proterozóico da sub-bacia de Sergipe, caracterizado por rochas metamórficas da Faixa Sergipana apresentando-se, de forma rugosa, fraturado e com zonas clássicas de grábens e horts. Atinge uma profundidade máxima de $3.500 \mathrm{~m}$. Ressalta-se nesta região a falha de borda entre as estações SE1-10 e SE111, um traço de falha entre as estações SE1-13 e SE1-14 exibido como uma anomalia resistiva e a linha de charneira da bacia, exibida na estação SE1-19.

A compartimentação central da seção (ressaltada nas cores vermelha e verde, resistividade variando valores entre 1 e $80 \mathrm{ohms} / \mathrm{m}$ ) envolve a deposição de sedimentos das sequências das fases sinéclise, pré-rifte e rifte da sub-bacia. Estas fases são formada essencialmente por sedimentos glaciais e continentais do Grupo Igreja Nova na fase de sinéclise, por pelitos e arenitos do Grupo Perucaba na fase pré-rifte e por pelitos, arenitos e conglomerados do G. Coruripe na fase Rifte. Apresentam-se em conformidade com o embasamento e fraturados em determinadas porções com rejeitos estimados em $1.000 \mathrm{~m}$. A porção superior do modelo nesta região identificou diversos resistores, interpretados como carbonatos sem subdivisão perante a estratigrafia.

Ressalta-se a excelente correlação com os mapas estruturais da bacia. Onde a seção atravessa, e marca, as regiões da falha de borda, do Baixo de Japaratuba, do cruzamento de falhas com o Alto de Carmópolis e a charneira da bacia, apresentando uma boa correlação com o trabalho de Lana (1990) (Figura 9).

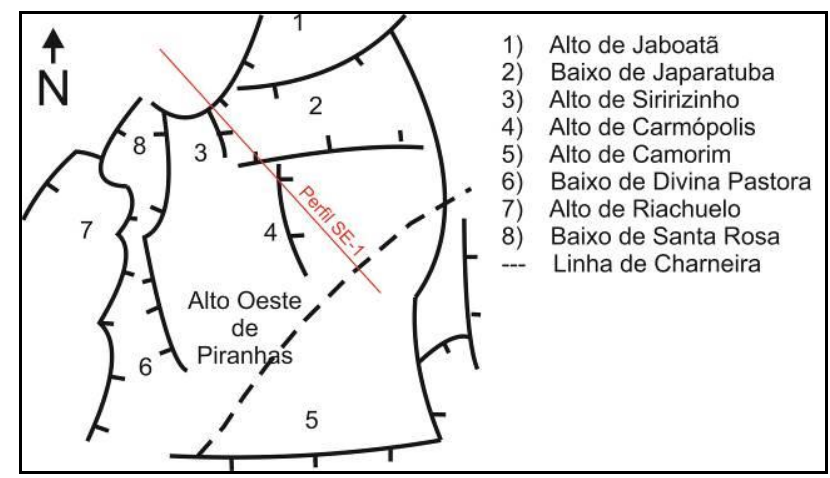

Figura 9: Principais estruturas da bacia sobrepostas com a seção MT amostrada. (Adaptado de Lana, 1990).

\section{Conclusões}

O modelo de resistividade $2 \mathrm{D}$ é bastante coerente no que diz respeito ao modelo estrutural presente na área. Algumas questões sobre os empurrões na Faixa Sergipana não puderam ser solucionadas, entretanto o 
${ }^{*}$ Gomes, K.C.P. ${ }^{3}$; Corrêa, E.O. ${ }^{1}$; de Lugão, P.P.L. ${ }^{1}$; Kriegshäuser, B.F. ; Menezes, A.M.C. ${ }^{1}$; Nunes, D.F. ${ }^{1}$; de Oliveirză A.R.R. ${ }^{1}$; da Rocha, L.M.S. ${ }^{1}$

${ }^{1}$ Strataimage Consultoria Ltda.

condutor observado entre a estação SE1-04 dá um indicativo sobre as chances de ocorrência de mineralizações metálicas e empurrões associados. Além da espessura dos sedimentos da Fm. Barreiras ser desprezível pela pequena espessura e não ser detalhada neste trabalho.

Em relação ao campo de Carmópolis e a Bacia de Sergipe-Alagoas, através do método foi possível definir os principais contrastes entre as estruturas regionais $e$, na área do campo de produção, foi possível definir um controle sobre reservatório, onde se observa uma estrutura condutiva com descontinuidade lateral, com resistores consideráveis sobrepostos.

Com base nestas informações e na seção elaborada, podemos prever plays exploratórios em condições semelhantes a esta porção do reservatório e ter novas ideias em relação ao uso do magnetotelúrico em diferentes escalas de exploração.

\section{Referências}

CAMPOS NETO OPA, LIMA WS \& CRUZ FEG. 2007. Bacia de Sergipe-Alagoas. Boletim de Geociências da Petrobrás, Rio de Janeiro, 15 (2): 405-415.

LANA MC. 1990. Bacia de Sergipe-Alagoas: uma hipótese de evolução tectono-sedimentar. In: GABALIA GPR \& MILANI EJ (Eds.). Origem e Evolução das Bacias Sedimentares Brasileiras. Ed. Gávea/Petrobrás, Rio de Janeiro, vol. 1, 311-332.

MILANI EJ \& ARAÚJO LM. 2003. Recursos Minerais Energéticos: Petróleo. In: BIZZI LA, SCHOBBENHAUS C, VIDOTTI RM \& GONÇALVES JH (Eds.). Geologia, Tectônica e Recursos Minerais do Brasil. CPRM, Brasília, Brazil, 541-576.

SIMPSON, F. \& BAHR, K, 2005. Practical Magnetotellurics, CAMBRIDGE UNIVERSITY PRESS, $255 \mathrm{pp}$.

TEIXEIRA LR, LIMA ES, NEVES JP, SANTOS RA, SANTIAGO RC, MELO RC. 2014. Mapa Geológico e de Recursos Minerais do Estado de Sergipe. CPRM/CODISE. Material Cartográfico. Escala 1:250.000. 


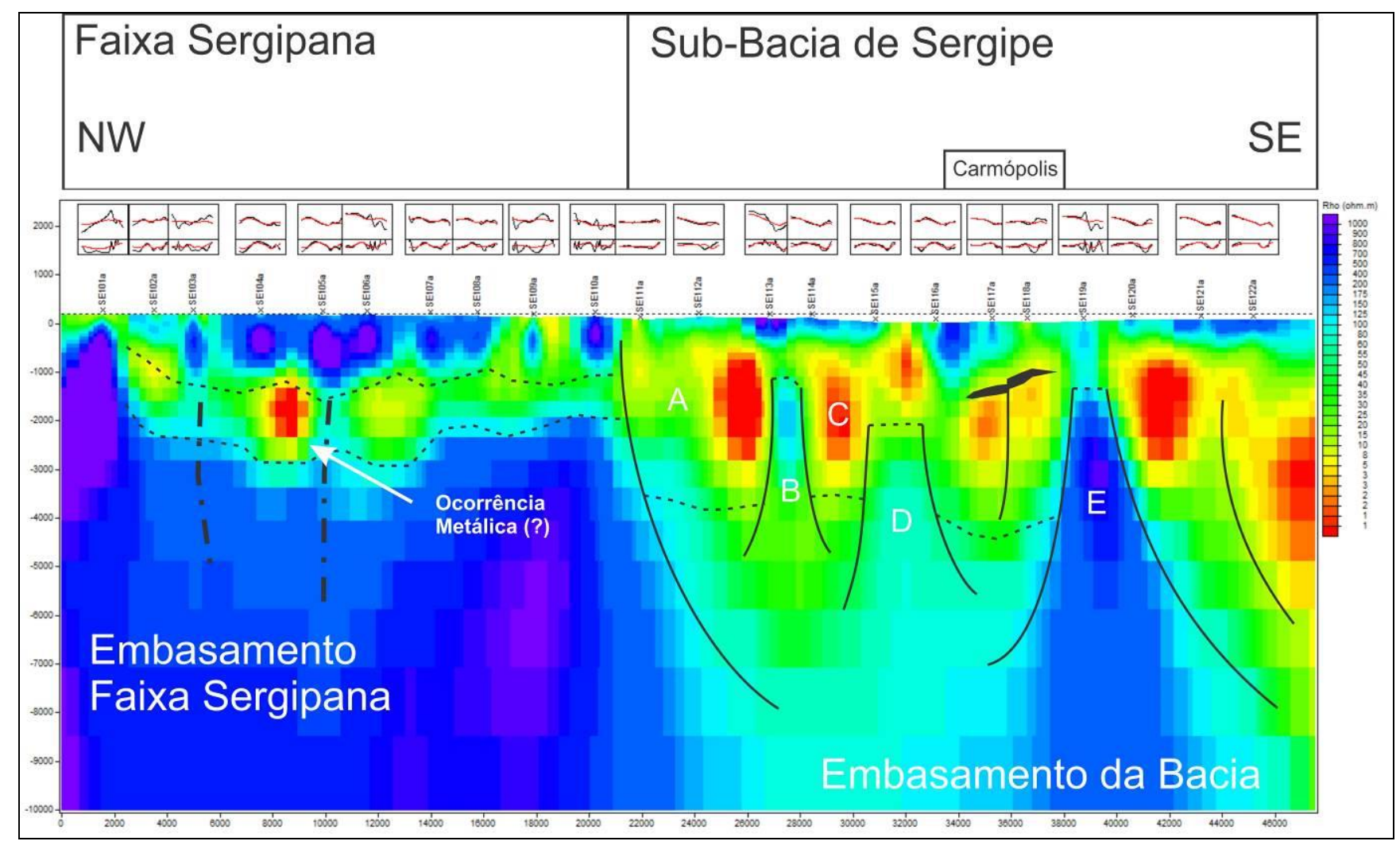

Figura 8: Modelo de Inversão 2D interpretado. Na Faixa Sergipana consegue-se limitar as unidades do Grupo Macururé, onde o topo mais resistivo corresponde às unidades de metaxistos quartzosos, a porção média corresponde às metassedimentos pelíticos, com anomalia condutiva condizente as ocorrências metálicas de manganês associadas a lineamentos e empurrões. Na Sub-Bacia de Sergipe foi possível correlacionar o modelo com as principais estruturas da região, sendo $A$ - Baixo de Japaratuba, $B$ - Zona de cruzamento entre as falhas do Baixo de Japaratuba com o Alto de Carmópolis, C - Zona de Interferência entre as falhas do Baixo de Japaratuba e Alto de Carmópolis, D-Alto de Carmópolis e E - linha de charneira da Bacia de Sergipe-Alagoas. 